\title{
O CAMINHO PARA O CONSENSO - ANÁLISE DA CRÍTICA DE WALDRON A RAWLS SOBRE DESACORDOS POLÍTICOS
}

\author{
The path to consensus - an analysis of Waldron's critique of \\ Rawls about political disagreement
}

El camino hacia el consenso - análisis de las críticas de Waldron a Rawls sobre los desacuerdos políticos

André Matos de Almeida Oliveira ${ }^{1}$ Universidade Federal de Minas Gerais, Belo Horizonte, MG, Brasil.

Pâmela de Rezende Cortes ${ }^{2}$ Universidade Federal de Minas Gerais, Belo Horizonte, MG, Brasil.

Renato César Cardoso ${ }^{3}$ Universidade Federal de Minas Gerais, Belo Horizonte, MG, Brasil.

\section{Resumo}

O objetivo deste artigo é analisar a crítica de Waldron a Rawls, feita no livro Law and Disagreement. Queremos saber se nessa crítica está implícita a ideia de que Rawls faz uma má idealização. Para fazer isso, teremos, em primeiro lugar, que esclarecer a rela-

\footnotetext{
1 Doutorando e Mestre em Direito pela UFMG. Bacharel em Direito pela UFMG. Email: andrematosalmeida@hotmail.com. ORCID: https://orcid.org/0000-0001-6791-0701

2 Doutoranda e Mestra em Direito pela UFMG. Graduada em Ciências do Estado pela UFMG. Bolsista CAPES. Email: pamela.recortes@gmail.com. ORCID: https://orcid.org/0000-0002-4938-5023

3 Professor associado, nos cursos de Direito e Ciências do Estado, da Faculdade de Direito da UFMG Doutor e mestre em Direito pela UFMG. Pós-doutor em Filosofia pela Universidade de Barcelona, Espanha. Bacharel em Direito pela UFMG e em Relações Internacionais pela PUC Minas (MG). E-mail: renatoccardoso@hotmail.com. ORCID: https://orcid.org/0000-0001-8374-6462
} 
ção entre "teorias ideais", aquelas que estipulam os princípios de justiça que devem ser alcançados para tornar justa uma sociedade $e_{2}$ "más idealizações", distorções conceituais ou falsificações de fatos que podem ser feitas por uma teoria. Falaremos sobre essas distinções na primeira seção do artigo. Waldron ataca a alegada incapacidade da teoria de Rawls de tratar seriamente os desacordos sobre os princípios políticos. A exposição dessa crítica e a análise de seu desenrolar vai ocupar as parcelas mais significativas do artigo, e será feita nas seções seguintes. Ao fim da análise, defenderemos que, apesar de a crítica de Waldron ser forte, ela não gera a implicação de que Rawls faz más idealizações.

Palavras-chave: Teorias ideais e não ideais de justiça. Justiça como equidade. Desacordos políticos. Filosofia política.

\begin{abstract}
Our aim in this paper is to analyze Waldron's critique of Rawls, made in the book "Law and Disagreement". We want to know if, implicit in the critique, lies the idea that Rawls was making a bad idealization. To do this, we need first clarify what is an "ideal theory" (as opposed to a non-ideal theory) and what are good or bad idealizations. We'll develop these distinctions in the first section of the text. Waldron attacks Rawls's alleged inability to seriously address the problem of disagreements on political principles. Exposing and analyzing the many aspects of this critique will occupy us on the remaining sections of the text. At the end of the analysis, we'll argue that, although Waldron's attacks were strong, we nonetheless have no reason to conclude that implicit on them rests the idea that Rawls was making bad idealizations.
\end{abstract}

Keywords: Ideal and non-ideal theories of justice. Justice as fairness. Political disagreement. Political philosophy.

\title{
Resumen
}

El objetivo de este artículo es analizar las críticas de Waldron a Rawls, hechas en el libro "Law and Disagreement". Queremos saber que si esta crítica está implícita en la ideia de que Rawls hace una mala idealización. Para ello, tendremos, en primer lugar, que aclarar la relación entre "teorías ideales", aquellas que estipulan los principios de justicia que deben ser alcanzados para hacer justa una sociedad, y "malas ideas", distorsiones conceptuales o falsificaciones de hechos que una teoría pueden ser hechas por una teoría. Vamos a hablar acerca de estas distinciones en la primera sección del artículo. Waldron ataca a la presunta incapacidad de la teoría de Rawls, de tratar graves desacuerdos en principios políticos. La exposición de esta crítica y el análisis 
de su desarrollo van a ocupar las partes más importantes del artículo y se realizará en las siguientes secciones. Al final del análisis, se defiende que, a pesar de la crítica de Waldron ser fuerte, ella no genera la implicación de que Rawls hace malas idealizaciones.

Palabras clave: Teorías ideales y no ideales de la justicia. Justicia como equidade. Desacuerdos políticos. Filosofía política.

\section{Introdução: teorias ideais e idealização}

A literatura sobre as teorias ideais e não ideais de justiça tem se expandido recentemente e muito se debate sobre o correto significado dos termos ${ }^{4}$. Não queremos nos aprofundar no debate aqui, mas, para fins de mapeamento do tema, é útil adaptar a distinção feita por Ingrid Robeyns. Ela diferencia dois âmbitos de atuação de teorias normativas: o da teoria ideal e o de abordagens não ideais (ROBEYNS, 2008) 5 .

Teorias ideais são aquelas que propõem "princípios que deveriam governar uma sociedade, isto é, [são as que] propõem e justificam um conjunto de princípios de justiça que deveriam ser alcançados antes que pudéssemos considerar certa sociedade justa" (ROBEYNS, 2008, p. 343, tradução nos$\mathrm{sa})^{6}$. O exemplo mais eminente de teoria ideal é a elaborada por Rawls em Uma Teoria da Justiça e em escritos posteriores. De fato, apesar de haver antecedentes filosóficos da distinção entre abordagens ideais e não ideais (YPI, 2010, p. 537), Rawls foi o autor que tornou a distinção mais explícita, posicionando a sua teoria claramente no lado "ideal” (ROBEYNS, 2008, p. 341).

Uma metáfora esclarecedora de Robeyns sobre o objetivo das teorias ideais trata da função de uma "mítica ilha paradisíaca" (ROBEYNS, 2008, p. 344-345). Uma ilha paradisíaca, por ser perfeita, é o lugar para onde

\footnotetext{
4 Cf., e.g., ROBEYNS, 2008; FARRELLY, 2007; SEN, 2006; MILLS, 2005; SIMMONS, 2010; HAMLIN; STEMPLOWSKA, 2012.

5 A divisão de Robeyns na verdade é tripartida, compreendendo teorias ideais, teorias não ideais e prescrições para design de ações e implementação. Para simplificar, no entanto, unificaremos os dois últimos itens da distinção.

6 Do original: principles of justice that should govern a society, that is, to propose and justify a set of principles of jus tice that should be met before we would consider a certain society just.
} 
todos querem ir. Apesar de não sabermos o caminho e de ninguém nunca ter aportado lá, esperamos com a maior ansiedade que mapas nos deem indicações de sua localização e nos indiquem possíveis caminhos para ela. Nunca saberemos se um dia chegaremos à ilha, mas sabemos que nosso objetivo último é estar lá, o que já é razão mais do que suficiente para especularmos sobre ela. Da mesma forma, não sabemos com clareza se e quando os princípios de uma teoria como a rawlsiana serão alcançados, mas sabemos que esses princípios governarão uma sociedade plenamente justa, nosso objetivo último. A tentativa de conhecê-los mais do que justifica nosso interesse por teorizações ideais de justiça.

Já as abordagens não ideais são, como dito, mais factuais. Elas são usadas, em primeiro lugar, para comparar duas situações sociais para decidir qual dentre elas é a mais justa ou qual delas se aproxima mais do ideal de justiça (ROBEYNS, 2008, p. 346). As abordagens não ideais também têm a importante função de mapear os meios empíricos pelos quais poderemos implantar as mudanças sociais necessárias para alcançar um estado de coisas mais justo (ROBEYNS, 2008, p. 349). Dando seguimento à metáfora, podemos dizer que as abordagens não ideais comparam rotas para a ilha paradisíaca, para escolher a melhor disponível; elas também buscam utilizar bem os instrumentos de navegação - velas, remos, bússolas etc. - que nos ajudarão a transitar pela rota escolhida.

Dentro ${ }^{7}$ do âmbito das teorias ideais há outra distinção importante e mais relevante aos nossos propósitos neste artigo. Trata-se de divisão entre boas e más idealizações. A distinção decorre da preocupação de filósofos de saber quando é adequado simplificar ou abstrair para elaborar uma teoria mais ampla. Ou seja, ela serve para responder à pergunta: "Quando é justificado fazer uma idealização"? Nesse ponto, devemos ter cuidado com os vários sentidos que o termo "idealização" pode ter. Ele

\footnotetext{
7 Mas talvez não exclusivamente nas teorias ideais. Pode ser que teorias não ideais também comportem algum grau de idealização.
} 
pode significar: "abstração"; "ideologia”; "estabelecimento de um fim último" e até (mais genericamente) "teoria ética" (MILLS, 2005, p. 166).

Mas, para nossos fins, é suficiente que direcionar a atenção para dois sentidos mais amplos. O primeiro, de idealização como mero ato de abstração: quando abstraímos, estamos simplificando situações fáticas complexas para criar um modelo mais simples que leve em conta apenas as variáveis relevantes para nossas metas teóricas. Abstraímos quando esboçamos, por exemplo, um mapa. Não precisamos tirar uma fotografia de uma rua, com todas as árvores, postes e fiações para fazer o mapa; nosso objetivo é mostrar rotas, então deveremos destacar apenas o traçado das ruas, mesmo que de forma mais abstrata, simplificada, esquemática. É evidente que não há nada de errado a priori com as abstrações; elas podem até ser essenciais para empreendimentos teóricos. Trabalhamos com "modelos" em todos os campos, desde os científicos mais especializados, como a física, até teorias sociais mais abertas (MILLS, 2005, p. 166-168).

O segundo sentido de idealização é negativo, pode significar "corrupção" ou "ideologia" (no sentido pejorativo do termo). Nesse caso, não estamos fazendo apenas uma simplificação inofensiva e útil de alguma variável fática; mais do que isso, estamos falsificando essa variável para encaixar, de forma coerente, a abstração daí resultante em nossa teoria, "empurrando a sujeira para debaixo do tapete". Por exemplo, se um agente público decidir implantar uma política pública no Brasil com base no pressuposto de que todos os agentes da sociedade estão em equilíbrio de poder, ignorando as circunstâncias que evidentemente falseiam essa pressuposição, como a grande desigualdade de renda no país e a existência de grupos com poder econômico concentrado ${ }^{8}$, então ele provavelmente estará fazendo uma abstração corrompida, uma má idealização.

Muitas teorias ideais de justiça são acusadas de fazer esse segundo tipo de idealização. Por exemplo, MILLS (2005) critica teorias liberais ideais por

\footnotetext{
8 E supondo, o que é importante, que se o tomador de decisão reconhecesse essas circunstâncias ele teria que modificar substancialmente ou até abandonar sua política pública.
} 
serem "ideológicas" - por inserirem sorrateiramente em suas abstrações sobre "cidadãos livres e iguais" características comuns somente a classes dominantes, marginalizando parcelas oprimidas, como mulheres e negros; FARRELLY (2007) critica as teorias de Rawls e Dworkin: segundo ele, as teorias geram más idealizações por serem cegas aos custos de proteção de liberdades básicas dos cidadãos; e VALENTINI (2009) afirma que a teoria multiculturalista de Kymlicka é defeituosa por não estabelecer formas de transformar as nossas atitudes nas circunstâncias não ideais nas atitudes necessárias para criar a situação ideal de justiça.

De forma semelhante, o nosso objetivo neste artigo é analisar uma crítica feita a um autor de uma teoria ideal. Estamos falando sobre a crítica feita por Waldron a Rawls, no livro Law and Disagreement (WALDRON, 1999). Waldron afirma que Rawls é incapaz de lidar seriamente com desacordos sobre princípios políticos. Queremos saber se essa crítica se encaixa no modelo "crítica por fazer (má) idealização" ou não.

A acusação de má idealização é particularmente poderosa porque leva à implicação de que o alvo da acusação está cometendo um erro conceitual que necessariamente o impedirá de resolver os problemas do mundo real. Uma teoria assim é natimorta. Mais do que isso, provavelmente haverá motivos para dizer que tal teoria agravará os problemas do mundo, já que é de se presumir que, se houver tentativas de aplicá-la, a concepção distorcida de realidade que ela carrega consigo gerará externalidades indesejáveis.

Logo, se a acusação de que Rawls faz más idealizações puder ser depreendida da crítica de Waldron (mesmo que implicitamente), então a crítica será mais devastadora do que inicialmente aparenta. A investigação desse problema nos permitirá entender com mais clareza a gravidade e a pertinência das considerações de Waldron. Abordaremos a crítica abaixo, mas, antes, precisamos saber como Waldron expõe a posição de Rawls sobre os desacordos políticos. 


\section{Waldron sobre Rawls e os desacordos políticos}

No capítulo cinco de Law and Disagreement, Waldron analisa as considerações teóricas de Rawls sobre desacordos políticos, presentes tanto em Liberalismo Político quanto em Uma Teoria da Justiça (WALDRON, 1999, cap. 5).

Waldron quer entender, em primeiro lugar, a relação entre (i) desacordos de princípios políticos e (ii) desacordos filosóficos abrangentes sobre o bem em uma comunidade pluralista (WALDRON, 1999, p. 149). Como ele quer entender essa relação em especial na teoria de Rawls, ele está usando esses termos no sentido rawlsiano. Na terminologia de Rawls, desacordos abrangentes, (ii), seriam aqueles mais profundos, decorrentes da reflexão contínua dos indivíduos sobre o valor último da vida, sobre seu significado, sua natureza etc. (WALDRON, 1999, p. 149). As diferenças religiosas seriam o exemplo mais evidente de um desacordo abrangente, mas há diversos outros casos, como os de conflito entre concepções hedonistas, utilitárias, de florescimento humano, virtuosistas, entre outras. Desacordos sobre princípios políticos, (i), restringem-se a conflitos sobre quais devem ser os princípios fundamentais políticos, de justiça e de direitos adotados pela comunidade.

Há dois modelos à primeira vista plausíveis para lidar com a relação entre esses dois tipos de desacordo (WALDRON, 1999, p. 149-150). No primeiro (a), podemos sustentar que os desacordos sobre princípios políticos decorrem dos desacordos de visão abrangentes de bem. Assim, haveria uma dependência entre os dois tipos de desacordo - os desacordos políticos seriam de alguma forma determinados pelos desacordos abrangentes. É plausível, por exemplo, pensar que as concepções abrangentes de bem dos muçulmanos os levarão a defender um conjunto de princípios políticos (sharia) que entrará em choque com os princípios políticos defendidos por católicos, que por sua vez são decorrentes de sua própria visão abrangente de bem.

No segundo modelo (b), os desacordos sobre princípios políticos, especialmente os sobre justiça, não dependem dos desacordos sobre concepções abrangentes de bem. Entre os argumentos sustentados por defensores desse segundo modelo está a afirmação de que questões de justiça seriam, 
de fato, levantadas exatamente tendo como objetivo solucionar os problemas sociais que surgem do conflito das visões abrangentes dos cidadãos.

O passo natural parece ser encaixar a teoria de Rawls no segundo modelo, já que ele expressamente rejeita o primeiro como adequado para a sua teoria de justiça como equidade e para teorias políticas liberais em geral (WALDRON, 1999, p. 150). Ele diz, por exemplo:

[O] problema do liberalismo político consiste em saber como é possível existir, ao longo do tempo, uma sociedade estável e justa de cidadãos livres e iguais, profundamente divididos por doutrinas religiosas, filosóficas e morais razoáveis. Tratase de um problema de justiça política, não de um problema sobre o bem supremo (RAWLS, 2000, p. 33).

Porém, segundo Waldron (1999, p. 151), tal conclusão poderia ser precipitada, porque partiria do pressuposto de que Rawls concorda com a ideia de que em uma sociedade bem-ordenada haverá desacordos sobre princípios de justiça. Mas não é possível ter certeza de que Rawls realmente concorde com essa ideia. Waldron afirma, por exemplo, que a atenção que Rawls dá a desacordos sobre justiça é "insignificante" (1999, p. 151), especialmente se a compararmos à atenção mais razoável que ele presta aos desacordos de concepções abrangentes de bem.

Para deixar as coisas mais claras, vale a pena desenvolver um pouco a visão de Rawls sobre desacordos nas visões abrangentes de bem. Para Rawls, é inadequado afirmar que essas discordâncias surgirão apenas porque indivíduos são autointeressados, egoístas ou irracionais. Não que esses não sejam fatores importantes (RAWLS, 2000, p. 101), mas eles não dão conta de tudo. Rawls quer entender como os desacordos surgem entre indivíduos racionais e razoáveis. Para isso, ele nos apresenta a ideia de "limites do juízo" (burdens of judgement), que são "os muitos acasos envolvidos no correto (e consciencioso) exercício de nossas faculdades de raciocínio e julgamento no curso normal da vida política" (RAWLS, 2000, p. 98). 
Rawls acredita que os limites do juízo nos levarão ao desacordo mesmo após o correto uso de nossos poderes de razão e da livre discussão racional na vida pública (RAWLS, 2000, p. 102). Indivíduos diferentes, por vários motivos, são formados com um conjunto de valores diferentes ou ordenam os valores comuns à sociedade de formas diferentes. Não há nenhuma irracionalidade ou mesquinhez que pode ser identificada nesse processo, pelo contrário: parte importante dos objetivos da teoria liberal é o respeito aos desacordos, elemento constitutivo de uma democracia.

Mas, voltando à questão apontada na página anterior, é preciso saber o que Rawls diz sobre desacordos sobre justiça, já que, ao menos à primeira vista, é evidente que esse tipo de desacordo - e não só os desacordos sobre visões abrangentes de bem - se encaixam no modelo dos limites do juízo. Como Waldron diz, é razoável - e esperado - pensar que em uma democracia surgirão as circunstâncias em que indivíduos razoáveis vão discordar sobre questões fundamentais de justiça, como "ações afirmativas, a legalização do aborto, os limites da liberdade de expressão, a extensão propícia de fornecimento de bem-estar e o papel do merecimento pessoal na justiça econômica" (WALDRON, 1999, p. 112).

O que Rawls nos diz sobre essa assimetria? Parece que nada. Não é que ele não aceite o fato evidente de que as pessoas discordam sobre essas questões nas sociedades atuais. Mas, quando a discussão é sobre sociedades bem-ordenadas, ele rapidamente nos direciona para a conclusão de que a ideia de limites do juízo nos leva a aceitar que desacordos de visões abrangentes são inevitáveis. Por exemplo, ele diz que:

A conseqüência evidente dos limites do juízo é que nem todas as pessoas razoáveis professam a mesma doutrina abrangente. Além disso, elas também reconhecem que todas as pessoas sem exceção, inclusive elas próprias, estão à mercê desses limites, e, embora muitas doutrinas abrangentes e razoáveis tenham seus defensores, não é possível que todas sejam verdadeiras (e é possível que nenhuma delas seja verdadeira). 
A doutrina que uma pessoa razoável professa é apenas uma doutrina razoável entre outras. Ao professá-la, é claro, a pessoa acredita que seja verdadeira, ou razoável, conforme o caso (RAWLS, 2000, p. 104, grifo nosso).

Rawls está correto nessa conclusão, mas, mais uma vez, é igualmente correto notar que ele

[e]m lugar nenhum [...] infere a conclusão igualmente evidente de que não podemos esperar que pessoas razoáveis concordem sobre o balanço adequado a ser designado na vida social para suas respectivas concepções abrangentes. Em lugar nenhum ele infere que, pelas mesmas razões, em uma sociedade bem-ordenada, pode ser esperado que pessoas razoáveis discordem fundamentalmente sobre os termos básicos e os princípios de sua associação'0 (WALDRON, 1999, p. 152, tradução nossa).

Por que Rawls estaria deixando escapar uma conclusão tão óbvia? Uma resposta possível leva em conta sua concepção de razão pública. $\mathrm{Na}$ razão pública estão as matérias em que os cidadãos são capazes de estar amplamente de acordo; questões fundamentais de justiça estariam entre elas. Isso fica claro quanto Rawls nos diz que as "questões relativas aos elementos constitucionais essenciais e à justiça básica, a estrutura básica e suas políticas públicas devem ser justificáveis perante todos os cidadãos, como requer o princípio da legitimidade política" (RAWLS, 2000, p. 274).

\footnotetext{
9 Para ver a discussão mais completa sobre os limites do juízo e visões abrangentes - e para ver que Rawls não desenvolve uma abordagem para os desacordos de justiça -, Cf. RAWLS, 2000, p. 98-110.

10 Do original: Nowhere [...] does he infer the equally evident conclusion that reasonable persons cannot be expected to agree about the proper balance to be assigned in social life to their respective comprehensive conceptions. Nowhere does he infer that for the same reasons, in a well-ordered society, reasonable people might be expected to disagree fundamentally about the basic terms and principles of their association.
} 
A justificação sobre essas questões deve ser feita apelando às "crenças gerais" dos cidadãos e às "formas de argumentação aceitas no momento presente e encontradas no senso comum". Argumentos assim seriam os únicos a ser admitidos na razão pública:

Tanto quanto possível, o conhecimento e as formas de argumentação que fundamentam nossa aceitação dos princípios de justiça e sua aplicação a elementos constitucionais essenciais e à justiça básica devem repousar sobre verdades claras, hoje amplamente aceitas pelos cidadãos em geral, ou acessíveis a eles. Caso contrário, a concepção política não ofereceria uma base pública de justificação (RAWLS, 2000, p. 274).

A conclusão relevante a se extrair daqui é que Rawls parece defender uma relação excludente entre limites do juízo e razão pública - ou seja, defender que quando um está presente o outro não pode estar. Quando se afirma que as formas de argumentação e o raciocínio na razão pública devem ser conhecidos por todos, presumivelmente devem-se excluir ideias escolhidas por mecanismos de raciocínio que "não são, e não podem ser, amplamente compartilhadas nesse sentido" (WALDRON, 1999, p. 152). Já vimos que ideias com essas características são precisamente as que são escolhidas sob os limites do juízo.

Então, se seguirmos a indicação de Rawls de razão pública nos termos apresentados, terminaremos com a conclusão peculiar de que em uma sociedade bem-ordenada os indivíduos não discordarão sobre as questões de justiça que devem ser discutidas politicamente. Para sermos mais sinceros, terminaremos com a conclusão de que não haverá política nesta sociedade bem-ordenada, já que consideramos "arena política" precisamente o local em que os indivíduos entram para apresentar, discutir e negociar suas discordâncias sobre princípios de política e justiça (WALDRON, 1999, p. 153).

Relutante de atribuir um posicionamento tão extremo a Rawls (WALDRON, 1999, p. 153), Waldron considera mais plausível interpretar 
que ele está dizendo que a ideia de razão pública é incompatível com a existência de desacordos razoáveis sobre os fundamentos da justiça. Os cidadãos concordarão com uma concepção geral razoável, mas discordarão sobre os detalhes da aplicação desses princípios. De fato, em Liberalismo Político Rawls afirma que, ao levar em consideração os valores da comunidade, podemos elaborar "uma família de concepções em cujos termos o liberalismo pode ser formulado e compreendido" (RAWLS, 2000, p. 87). Assim, ele concederia que nem todos os valores substantivos de sua concepção de justiça como equidade seriam adotados na razão pública.

Resta saber como definiremos o critério para identificar as discussões políticas compatíveis com a razão pública. Aqui, retornamos ao problema, porque Rawls não se intimida em oferecer os princípios gerais da justiça como equidade (valores expressos pelos princípios e diretrizes que seriam adotados na posição original) como $o$ critério adequado.

Para Waldron, "devemos parar um pouco para":

Considerar quão notável essa visão é. No mundo que conhecemos, pessoas definitivamente discordam - e discordam radicalmente - sobre justiça. Além disso, seus desacordos não são só sobre detalhes, mas sobre questões fundamentais. Há lugares em que Rawls reconhece essa diversidade. Ele diz, perto do início de Liberalismo Político, que 'nós nos voltamos para a filosofia política quando nossos entendimentos políticos compartilhados... deixam de funcionar'. No entanto, nas outras passagens que estamos discutindo, sua visão parecer ser de que essas diferenças devem ser levantadas e debatidas somente internamente ao meio dos 'princípios e guias gerais... acordados na posição original'. Pode ele realmente estar querendo dizer isso? Importante como a concepção de Rawls tem sido, todos nós sabemos que existe apenas um punhado de filósofos políticos acadêmicos que aceitam a ideia da posição original como Rawls a expõe ou sua visão dos princípios e guias gerais contidos nela. Parece estranho 
selecionar essa concepção extraordinariamente controversa como a base da visão de alguém sobre a razão pública, isto é, como a base da visão normativa de alguém sobre os termos em que os cidadãos podem adequadamente conduzir e tentar resolver uns com os outros seus desacordos sobre justiça. Mais abstratamente, é certamente um erro identificar as normas que moldam o debate público sobre a justiça com os valores e princípios que são constitutivos (mesmo se somente constitutivos em linhas gerais, sem contar constitutivos em detalhe) de uma posição particular nesse debate ${ }^{11}$ (WALDRON, 1999, p. 153-154, grifo do autor, tradução nossa).

\section{Então, é no mínimo uma aposta arriscada escolher uma concepção} que está longe de ser consensual para ser a regra do jogo nas discussões políticas. E, se optarmos por correr esse risco, será mais do que temerário - para não dizer errado - identificar as regras justamente com uma posição que está em discussão dentro desse jogo político.

Rawls reconhece que a sua sugestão é controversa, que é “inevitável e muitas vezes desejável que os cidadãos tenham visões diferentes no que diz respeito à concepção política mais apropriada". Mas ele afirma que as diversas concepções concorrentes para regular os debates na razão

$"$ Do original We should pause to consider how remarkable this view is. In the world we know, people definitely disagree - and disagree radically - about justice. Moreover their disagreement is not just about details but about fundamentals. There are places where Rawls acknowledges this diversity. He says near the beginning of Political Liberalism that '[w]e turn to political philosophy when our shared political understandings... break down'. However, in the other passages we have been discussing, his view seems to be that these differences are to be aired and debated only within the medium of 'principles and guidelines... agreed on in the original position'. Can he really mean that? Important though Rawls's conception has been, we all know that there is barely a handful of academic political philosophers who accept the original position idea as Rawls expounds it or his view of the principles and guidelines that would be accepted therein. It seems odd to select this extraordinarily controversial conception as the basis of one's view of public reason, that is, as the basis of one's normative view about the terms in which citizens may properly conduct and attempt to resolve their disagreements with one another about justice. More abstractly, it is surely a mistake to identify the norms framing the public debate about justice with values and principles which are constitutive (even if only broadly constitutive, let alone constitutive in detail) of a particular position in that debate. 
pública devem ser selecionadas e comparadas: "Um debate ordenado entre elas ao longo do tempo é uma forma confiável de descobrir qual é a mais razoável, se alguma o é" (RAWLS, 2000, p. 277).

No entender de Waldron, Rawls está nos propondo que a ideia de que à primeira vista (ex ante) várias concepções concorrentes seriam candidatas razoáveis para regular os debates na razão pública. Deveríamos então submeter todas essas visões aos argumentos e realizar debates na filosofia política para descobrir qual delas é a mais adequada. No final desse debate filosófico, a posição mais adequada emergiria (se alguma emergisse), e então nesse caso poderíamos falar de uma opção melhor posterior (ex post), que deverá ser aceita por todos como a reguladora do debate. Posteriormente, então, não haverá mais discordância sobre os fundamentos da justiça, mas somente sobre os detalhes da aplicação de sua concepção geral (WALDRON, 1999, p. 154).

$\mathrm{O}$ que podemos pensar disso tudo? Até agora fizemos um resumo de como Waldron apresenta a posição de Rawls. A partir daqui, vamos ver como Waldron a critica e, mais especificamente, na próxima seção, se sua crítica contém a acusação de que Rawls faz alguma forma de (má) idealização.

Waldron enfatiza, em primeiro lugar, que, mesmo que concordemos com os argumentos acima, temos que nos lembrar de que tudo que Rawls está dizendo se aplica apenas a circunstâncias ideais, em que os cidadãos aquiescem estritamente às normas sociais: nas circunstâncias atuais, estamos muito longe de cumprir esses requisitos. Mas desenvolveremos esse ponto abaixo. Fora isso, a principal crítica de Waldron ao argumento de Rawls é que ele corre sério risco de misturar de forma inadequada argumentos sobre justiça e argumentos sobre política.

Para Waldron, Rawls faz um bom trabalho quando escreve sobre justiça. Ele vê com bons olhos a concepção da justiça como equidade e não tem nada contra os argumentos de Rawls na medida em que eles sejam uma defesa de uma concepção de justiça. No plano teórico - o plano em que se costuma desenvolver discussões sobre justiça - não há nenhum problema em se argumentar do jeito que filósofos tipicamente argumentam: apresentando sua teoria como única e melhor posição possível (mesmo 
que se admita que o seja pelo menos entre aquelas que são conhecidas até agora) e clamando superioridade sobre as concorrentes. Filósofos não são ingênuos e sabem que os seus companheiros farão exatamente a mesma coisa. Mas, mesmo assim, a expectativa geral é de que o debate seja frutífero, no mínimo eliminando posições ruins e rendendo bons argumentos.

Mas essa estratégia não pode ser imitada na arena política (pelo menos em todas as arenas políticas democráticas das quais tivemos notícia até hoje). Por isso, para Waldron, Rawls não faz um trabalho tão bom assim ao falar sobre política12 (WALDRON, 1999, p. 159-160). Acreditar que podemos apresentar diversas teorias de justiça no campo político e depois realizar um debate argumentativo em que provavelmente emergirá uma teoria ex post vencedora (no caso, com mais probabilidade ainda, a própria teoria rawlsiana) é negar a ideia que Waldron chama de "circunstâncias da política".

Waldron ironicamente se inspira em Rawls para formular a sua concepção de "circunstâncias da política" (WALDRON, 1999, p. 102). No caso, a inspiração provém do conceito rawlsiano de "circunstâncias de justiça"13. Estaremos em circunstâncias de justiça em todo arranjo social em que houver moderada escassez de recursos e altruísmo limitado entre cidadãos. Fora desse meio termo não é possível que haja justiça porque estaremos ou em situações que deixam a justiça supérflua (abundância ilimitada; altruísmo ilimitado) ou em situações que a fazem impossível (privação completa; egoísmo cego).

As circunstâncias da política também são um meio termo (WALDRON, 1999, p. 101-102): por um lado, os cidadãos discordam entre si sobre quais são os princípios políticos adequados para a comunidade; por outro, eles estão plenamente conscientes de que, apesar do desacordo, ainda assim precisam estabelecer mecanismos de decisão que viabilizem cursos de ação compartilhados, organizados e harmônicos. Como no caso das circunstâncias

\footnotetext{
12 Apesar de o foco principal da crítica de Waldron ser o livro Liberalismo Político, ela se aplica igualmente ao livro Uma Teoria da Justiça. Em Uma Teoria da Justiça, Rawls constrói as instituições já partindo do pressuposto de que divergências sobre os fundamentos da justiça estão substancialmente eliminadas (WALDRON, 1999, p. 157).

13 Que Rawls, por sua vez, extraiu em boa parte de Hume. Cf. RAWLS, 2005, p. 126, nota 3.
} 
da justiça, as circunstâncias da política seriam supérfluas em um extremo (há necessidade de cursos de ação, mas não há desacordos) e impossíveis no outro (há desacordos, sem tomada de decisão). Como Waldron diz:

O que normalmente é entendido por política é uma arena em que os membros de algum grupo debatem e encontram formas de chegar a decisões sobre vários problemas apesar do fato de eles discordarem sobre os valores e princípios que os méritos desse problema envolvem ${ }^{14}$ (Ibidem, p. 159).

Logo, como atualmente estamos indubitavelmente em circunstâncias da política, é impossível que a posição de Rawls seja aplicável, precisamente por ser cega a um dos elementos constitutivos da política - os desacordos entre os cidadãos sobre questões fundamentais de justiça.

Waldron defende a posição de que podemos - e devemos - separar nossa adesão enfática a uma concepção fundamental de justiça de nossa atuação política (WALDRON, 1999, p. 160). Em alguns momentos teremos que ceder e aceitar como correto politicamente um resultado que consideramos injusto, já que ele foi decidido pelos procedimentos políticos adequados da comunidade. Disso não se conclui que consideramos a política como mais importante do que a justiça - uma conclusão assim origina-se de uma falsa dicotomia. Concordaremos com o resultado político que consideramos injusto porque saberemos que estamos nas circunstâncias da política - saberemos que em alguns momentos é mais importante que haja uma decisão comum, mesmo havendo desacordo sobre qual será a melhor decisão. Assim, argumentar que a posição escolhida nesse procedimento é injusta é argumentar em círculo, porque o que está em jogo é exatamente um mecanismo que opera - chega a decisões - enquanto há discordâncias sobre qual é o resultado justo (WALDRON, 1999, p. 161).

\footnotetext{
14 Tradução livre de: "What is normally understood by politics is that it is an arena in which the members of some group debate and find ways of reaching decisions on various issues in spite of the fact that they disagree about the values and principles that the merits of those issues engage."
} 
Veremos, na seção a seguir, se dessa crítica podemos concluir que Waldron afirma que Rawls está fazendo uma (má) idealização.

\section{A possibilidade de (más) idealizações}

Talvez o ponto crucial para conferirmos se Waldron, em sua crítica, acredita ou não que Rawls está fazendo uma má idealização é o de saber se é possível, em discussões sobre princípios políticos, transitar da situação de limites do juízo e desacordos disseminados para a situação em que se instala uma razão pública que comporta as discussões dos temas constitucionais essenciais e da justiça' ${ }^{15}$. Eles só não alcançarão a razão púbica. A transição é importante no liberalismo político porque garante o assentimento dos cidadãos e a legitimidade do sistema.

Podemos rapidamente recapitular a nossa discussão anterior. Como vimos na primeira seção, uma característica importante que distingue uma boa de uma má idealização é ela poder ser reaproximada aos fatos sem ter sofrido distorções que, se corrigidas, inviabilizariam a idealização. Então, se a proposta de Rawls não é uma má idealização, ela deve, de alguma forma, se conectar a nossas circunstâncias atuais, dando conta de explicar com o mínimo de plausibilidade a transição para a situação ideal.

Na seção anterior, também vimos que Rawls propõe o conceito de limites do juízo, a noção de que as pessoas, mesmo que razoáveis e racionais, discordarão sempre sobre quais concepções abrangentes de bem são as corretas. Esse conceito de Rawls é um pouco mais realista, pois descreve adequadamente nossas circunstâncias sociais atuais.

Por outro lado, Rawls também propõe a ideia de razão pública, em que os cidadãos discutirão questões relevantes para a comunidade partindo de vários pressupostos comuns sobre os fundamentos da justiça. Não é que Rawls negue que haverá discordâncias sobre questões de justiça na razão

15 Vale lembrar que os limites do juízo continuarão incidindo sobre os cidadãos, mesmo em circunstâncias ideais. Eles só não alcançarão a razão pública. 
pública; ele nega, no entanto, que haverá discordâncias fundamentais sobre as questões de justiça. Mas, como, em nossas circunstâncias atuais, ainda há discordâncias fundamentais e disseminadas sobre questões de justiça (e como parece que ainda estamos muito distantes de uma situação na qual essas discordâncias vão diminuir significativamente), é adequado dizer que a ideia de razão pública de Rawls é (ou está muito próxima de ser) ideal.

Reconhecer esses pontos já é suficiente para afirmar que as ideias de limites do juízo e de razão pública não podem funcionar ao mesmo tempo e no mesmo lugar. Nas circunstâncias em que a razão pública funciona, os limites do juízo não podem entrar em ação (ou devem entrar em ação de forma muito mitigada), e vice-versa. O conceito de limites do juízo não é ideal (mas também não precisa ser não ideal).

Assim, fica claro que, em nossa análise, o ponto crucial é o da transição da situação (não ideal) de desacordos disseminados para a situação (ideal) da razão pública. Se Waldron (i) considera essa transição como utópica ou impossível, podemos concluir que ele considera que Rawls está fazendo uma má idealização. Se Waldron considera (ii) a transição possível (mesmo admitindo que ela seja muito difícil), então podemos concluir que ele considera que Rawls não está fazendo uma má idealização.

Qual é a posição de Waldron? Inicialmente, nós pensávamos que havia fortes indícios de que Waldron considerava que Rawls fazia uma má idealização, ou seja, que ele estava defendendo a primeira alternativa, (i). Porém, após uma leitura mais atenta, agora acreditamos que as evidências favorecem uma interpretação compatível com a segunda alternativa, (ii). Veremos os motivos disso a seguir, mas, antes, devemos enfatizar um ponto importante, e que foi crítico para podermos mudar a nossa opinião. Waldron adere à segunda alternativa, mas nos urge, por outro lado, a tomar muito (muito!) cuidado ao tentar aplicar uma teoria feita para uma situação de consenso quase utópica a nossa situação não ideal e conflitante atual. Ou seja, o que temos que ter em mente é que, mesmo não considerando que Rawls não faz uma má idealização, ainda é possível que Waldron seja de 
alguma forma pessimista com a possibilidade de aplicação da teoria em nossas circunstâncias atuais. Mas isso também ficará mais claro a seguir.

Seguindo com a questão da má idealização, vemos, em primeiro lugar, que Waldron reconhece a importância da separação conceitual entre teorias ideais e não ideais, dizendo que os dois termos, no sentido rawlsiano, denotam uma distinção entre a assunção de aquiescência estrita (strict compliance) e aquiescência parcial (partial compliance) dos cidadãos aos princípios que governam a estrutura básica (WALDRON, 1999, p. 158). Ou seja, no modelo ideal, os cidadãos, de forma cooperativa e por causa de seu senso de justiça compartilhado, obedecem estritamente às regras da estrutura básica; no modelo não ideal, a obediência não é ampla - e nesse caso há margem para a origem de injustiças (RAWLS, 2005, p. 8). Waldron conclui que daí se segue que:

A aplicação de seu argumento para uma sociedade como a nossa, em que as pessoas não aceitam nem pensam nelas mesmas como aceitando os mesmos princípios de justiça é problemática. Nossa sociedade é uma em que a política é dedicada bem explicitamente a lidar com desacordos fundamentais sobre justiça. Por essa razão, ela não é uma sociedade bem-ordenada no sentido de Rawls ${ }^{16}$ (WALDRON, 1999, p. 158, grifo do autor, tradução nossa).

Então vemos que Waldron acredita que haverá "aplicação problemática" dos princípios rawlsianos se não levarmos em conta seriamente a divisão entre sociedades de aquiescência estrita e sociedades de aquiescência parcial (ideais e não ideais). Ou seja, a passagem é um alerta sobre o risco de confundir a aplicabilidade dos princípios de justiça no âmbito ideal e no âmbito não ideal. Mas o alerta termina aí. Nada do que foi dito nos fornece evidência para pensar que Waldron dá um passo a mais e conclui que Rawls faz uma má idealização.

16 Do original: [T] he application of his arguments to a society like ours, in which people neither accept, nor think of themselves as accepting, the same principles of justice is quite problematic. Ours is a society whose politics are dedicated quite explicitly to grappling with fundamental disagreements about justice. For this reason, it is not a well-ordered society in Rawls's sense. 
Uma evidência mais categórica de que Waldron não acredita que Rawls faz necessariamente uma má idealização se torna aparente quando percebemos que ele concede que Rawls propôs um caminho minimamente plausível de transição de uma situação não ideal para a ideal - ou seja, um caminho para nos aproximarmos do consenso na razão pública.

Há, de fato, uma forma de trilhar esse caminho. Para entendê-la, temos que pensar nas semelhanças e nas diferenças da divisão rawlsiana entre um "consenso sobreposto" e um "modus vivendi"n7. A semelhança entre os dois termos está no fato de que eles se referem à relação entre múltiplas concepções abrangentes de bem e um único sistema de princípios de justiça.

A diferença entre os dois termos surge porque, enquanto no modelo de modus vivendi as pessoas com diversas concepções diferentes de bem vivem sob os mesmos princípios de justiça apenas por acidente, no modelo de consenso sobreposto, por sua vez, as pessoas com diversas concepções diferentes de bem vivem sob os mesmos princípios porque todas compartilham as mesmas razões normativas fortes para sustentá-los. Elas aceitam o liberalismo político pelas razões certas. Isso faz com que uma situação de consenso sobreposto seja estável, já que está ancorado em razões compartilhadas entre os cidadãos; o modus vivendi é mais instável, por ser uma sobreposição fortuita de assentimentos (WALDRON, 1999, p. 162).

O ponto é que Rawls, em Liberalismo Político, parece acreditar que uma concepção liberal pode se estabelecer primeiro como um modus vivendi, mas

\footnotetext{
17 Rawls também discute a ideia de consenso constitucional, proposta por Baier (1989). Essa ideia seria a de uma situação em que os cidadãos discordam sobre as questões fundamentais de justiça, mas concordam sobre a legitimidade dos procedimentos legislativos e judiciais para a solução dos desacordos. Para Baier, sociedades democráticas atuais estariam muito mais próximas de um consenso constitucional do que de um consenso sobreposto. Rawls considera que essa ideia funciona como intermediária entre os modus vivendi e o consenso sobreposto, mas não como ponto de chegada de uma sociedade bem-ordenada. Ela seria rasa e restrita demais, não teria recursos conceituais suficientes para solucionar questões de estabilidade e legitimidade mais profundas. No consenso sobreposto, por sua vez, seria possível lidar com essas questões porque ele se baseia em concepções de pessoa e de sociedade que fundamentam uma cultura política (RAWLS, 2000, p. 205-216). Não incluiremos as considerações sobre a ideia de consenso constitucional no seguimento da discussão porque Waldron não a aborda em Law and Disagreemen".
} 
depois se tornar um consenso sobreposto. Waldron (WALDRON, 1999) propõe que interpretemos essa crença do seguinte modo: imaginemos que em uma sociedade há diversos cidadãos que sustentam diferentes concepções de bem (algo como: B1, B2, B3... Bn, para o número de concepções de Bem, "B"). Presumivelmente, cada concepção de bem implica uma concepção de justiça peculiar àquela concepção, de forma que cada concepção de bem virá acompanhada de uma concepção de justiça que será concorrente das outras concepções de justiça, inclusive a concepção liberal (algo como: $\mathrm{B} 1 \rightarrow J_{1}, B_{2} \rightarrow J_{2}, B_{3} \rightarrow J_{3}$, e assim por diante, com "J" denotando concepções de Justiça concorrentes). A ligação inseparável entre as concepções de bem e as concepções de justiça diferentes gera o que Rawls chama de concepções filosóficas abrangentes (algo como: $B 1+J_{1}=A 1, B 2+J_{2}=A 2, B 3+J_{3}=A 3$ etc., com " $A$ " denotando concepções filosóficas Abrangentes).

Agora suponhamos que uma concepção liberal de justiça, e.g., a Justiça Como Equidade (que abreviaremos para "JCE"), entre no jogo e que ela, em princípio, possa formar um consenso sobreposto com as diversas concepções de bem B1, B2... etc. A aliança que as concepções de Justiça J1, J2, J3 etc. poderão fazer com JCE será apenas de modus vivendi, porque elas são concorrentes entre si e não podem compartilhar os mesmos fundamentos normativos. Da mesma forma, as concepções filosóficas abrangentes também não poderão ser totalmente compatíveis com a concepção liberal JCE (já que as concepções de justiça, J, são parte integrante das concepções filosóficas abrangentes, A).

No entanto, se a concepção liberal se mantiver por tempo suficiente como modus vivendi, pode ser que comece a ficar explícito para os cidadãos que as suas concepções de justiça J1, J2, J3... etc. são redundantes. Será possível então que os cidadãos comecem a dividir as suas concepções filosóficas abrangentes ( $A 1, A 2$, etc.), antes unificadas, entre concepções de bem (B1, B2, etc.) e concepções de justiça $\left(J_{1}, J_{2}\right.$, etc.), e que eles discretamente, gradualmente, abandonem as concepções diferentes e concorrentes de justiça em favor da justiça como equidade. Nesse caso, então, os cidadãos continuariam a adotar as suas concepções de bem, mas 
desta vez em conjunto com a concepção liberal de justiça como guia de princípios políticos. A transição da concepção liberal de um mero modus vivendi para um consenso sobreposto estaria completa.

Essa, então, parece ser a forma pela qual Waldron acredita que é possível transitar de uma situação não ideal para uma situação ideal de aplicação dos princípios rawlsianos. Não sabemos o quão plausível Waldron acha que essa transição é. Intuímos que pouco. De qualquer forma, sabemos que ele é muito cauteloso ao falar sobre ela. Vejamos, por exemplo, como Waldron termina sua análise da transição para a teoria liberal de Rawls:

Essas especulações sobre o desaparecimento dos desacordos razoáveis sobre justiça em uma sociedade bem-ordenada não nos deve cegar para o fato de que fortes desacordos sobre justiça permanecem como a condição mais notável de nossa política. Nessas circunstâncias, devemos ser muito cautelosos ao inferir qualquer coisa para nossa política - incluindo nossa jurisprudência constitucional - da possibilidade puramente teórica de uma sociedade bem-ordenada como Rawls a entende ${ }^{18}$ (WALDRON, 1999, p. 163, tradução nossa).

Mas para os propósitos deste artigo é suficiente enfatizar o fato de que Waldron considera a transição possível. Isso já é uma evidência significativa de que Waldron não considera a concepção de consenso sobre os princípios políticos de Rawls como (má) idealização. Logo, podemos pensar que Waldron não considera que Rawls faz más idealizações e, assim, podemos concluir que Rawls está livre (pelo menos em relação a Waldron) dos efeitos devastadores que uma acusação de má idealização pode gerar. Mas podemos

\footnotetext{
18 Do original: However, these speculations about the withering away of reasonable disagreement about justice in a well-ordered society should not blind us to the fact that full-blooded disagreement about justice remains the most striking condition of our own politics. In these circumstances, we should be very careful about inferring anything for our politics - including our constitutional jurisprudence - from the purely theoretical possibility of a well-ordered society as John Rawls understands it.
} 
dizer, após tudo que vimos até aqui, que Rawls ficaria satisfeito com a análise de Waldron sobre a transição da situação não ideal para sua teoria ideal?

Há razões para duvidarmos disso. Como dissemos acima, Waldron pode não considerar que Rawls faça uma má idealização, mas pode, mesmo assim, pensar que é extremamente difícil chegar ao ponto em que a justiça como equidade será viável. Por isso, ele põe ênfase persistente na incapacidade desse ideal de justiça de lidar, de quase qualquer forma razoável, com os desacordos políticos atuais. Temos que lembrar que Rawls tinha uma preocupação genuína com o desacordo e o pluralismo afinal, podemos recordar, a escrita de Liberalismo Político pode ser vista em parte como uma tentativa de correção de percurso de seu livro mais importante anterior, Uma Teoria da Justiça. Liberalismo Político foi a tentativa de Rawls de construir uma teoria que levasse seriamente em conta as inescapáveis discordâncias sobre as concepções abrangentes de bem entre os cidadãos (WALDRON, 1999, p. 158).

Outro problema é que Rawls não parece compartilhar a opinião de Waldron (também recorrente) de que as suas teorias estariam tão distantes assim das circunstâncias atuais das sociedades democráticas ocidentais. Rawls, claro, reconhece que sua teoria é ideal, mas ele está sempre disposto a comparar o quadro esboçado nela com as condições vigentes nos Estados Unidos de sua época (WALDRON, 1999). O fato de ele estar disposto a utilizar a sua concepção de justiça como parâmetro de correção e como referência para propositura de reformas e remédios para injustiças contemporâneas é evidência de que ele tacitamente aceita que ela é sensível a fatos e pode guiar para políticas de nossa época. As críticas de Waldron parecem bloquear essa possibilidade, fazendo com que a teoria de Rawls seja aceitável como critério de análise social somente em um futuro bem mais distante.

Waldron parece acreditar que uma teoria política só é viável quando toma os desacordos de justiça como inescapáveis, tão inescapáveis quanto os desacordos sobre concepções abrangentes de bem. Isso é parte essencial das circunstâncias da política: como vimos, uma das tarefas fundamentais da política é fazer cidadãos cooperarem, mesmo 
discordando sobre o bem e sobre justiça. Como Waldron diz: "Também temos que lidar com o pluralismo-de-justiça e com desacordos sobre direitos. Pode ser que seja exigido que a filosofia política acomode essas circunstâncias também" (WALDRON, 1999, p. 158).

\section{Considerações finais}

Neste artigo, expusemos as críticas de Waldron a Rawls sobre as deficiências da teoria da justiça como equidade, em especial quando ela lida com desacordos políticos.

Vimos que há uma distinção rawlsiana entre concepções abrangentes de bem e concepções políticas de justiça e que há, também, duas formas de relacionar os desacordos nessas duas concepções: a primeira, determinista (desacordos nas concepções de justiça são dependentes dos da concepção de bem) e a segunda, não determinista (desacordos nas concepções de justiça são independentes dos da concepção de bem). À primeira vista, parece que Rawls endossa a segunda posição, mas vimos que essa hipótese é duvidosa, porque Rawls parece não pressupor que haverá desacordos sobre questões fundamentais da política em uma sociedade bem-ordenada regida pelos princípios de justiça.

Vimos também que há uma diferença, na teoria de Rawls, entre os limites do juízo, situação que originará desacordos razoáveis, e a situação da razão pública, em que os cidadãos compartilharão premissas argumentativas. Rawls acredita que em uma sociedade não haverá desacordos fundamentais sobre justiça porque as discussões sobre elas serão resolvidas na razão pública. O cenário ideal e resultante na discussão entre os cidadãos é o de consenso sobreposto, em que os cidadãos concordam sobre as questões fundamentais de justiça pelas razões corretas, o que torna o sistema político e o Estado legítimos.

Waldron considera inadequado pressupor, em qualquer circunstância parecida com as atuais, que os indivíduos estão livres dos limites do juízo em discussões sobre questões políticas fundamentais. Por isso, ele considera 
que a teoria de Rawls, nesse aspecto, só poderá ser aplicável no longo prazo. Waldron reconhece a distinção entre teorias ideais e não ideais: a teoria de Rawls, como estabelece princípios perfeitamente justos para uma sociedade bem-ordenada e com aquiescência estrita, seria ideal. Mas isso não significa que Waldron considera que a teoria de Rawls seja idealizada. Isto é, ele não considera que Rawls faça más idealizações, entendidas por nós como abstrações que distorcem os fatos para encaixá-los nas concepções teóricas do autor.

O motivo mais forte para chegamos à conclusão de que Waldron não acredita nisso é o fato de ele expor uma forma pela qual é minimamente plausível pensar que transitaríamos de nossa situação não ideal para a situação ideal. Essa forma é a transformação da aceitação dos princípios de justiça apenas como um modus vivendi para uma aceitação mais forte, em um consenso sobreposto. Logo, para Waldron, a teoria de Rawls não seria idealizada, porque, apesar de ela nos mostrar um cenário muito distante do atual, pelo menos nos indica que essa aproximação é possível, ao explicar como a transição de um cenário para outro se daria.

\section{Referências}

BAIER, Kurt. Justice and the aims of political philosophy. Ethics, Chicago, III, v. 99, n. 4, p. 771-790, 1989. https://doi.org/10.1086/293121

FARRELLY, Colin. Justice in ideal theory: A refutation. Political Studies, Oxford, v. 55, n. 4, p. 844-864, 2007. https://doi.org/10.1111/j.1467-9248.2007.00656.x HAMLIN, Alan; STEMPLOWSKA, Zofia. Theory, ideal theory and the theory of ideals. Political Studies Review, [S. l.], v. 10, n. 1, p. 48-62, 2012. https://doi. org/10.1111/j.1478-9302.2011.00244.x

MILLS, Charles W. "Ideal theory" as ideology. Hypatia, [S. l.], v. 20, n. 3, p. 165-183, 2005. https://doi.org/10.1111/j.1527-2001.2005.tbo0493.x

RAWLS, John. A theory of justice (Original ed.). Cambridge: Belknap, 2005.

RAWLS, John. O liberalismo politico. 2. ed. Rio de Janeiro: Ática, 2000.

ROBEYNS, Ingrid. Ideal theory in theory and practice. Social Theory and Practice, Tallahassee, Fla., v. 34, n. 3, p. 341-362, 2008. https://doi.org/10.5840/ soctheorpract 200834321 
SEN, Amartya. What do we want from a theory of justice? The Journal of philosophy, [S. l.], v. 103, n. 5, p. 215-238, 2006. https://doi.org/10.5840/ jphil2006103517

SIMMONS, A. John. Ideal and nonideal theory. Philosophy \& Public Affairs, [S. l.], v. 38, n. 1, p. 5-36, 2010.

VALENTINI, Laura. On the apparent paradox of ideal theory. Journal of Political Philosophy, [S. I.], v. 17, n. 3, p. 332-355, 2009. https://doi.org/10.1111/ j.1467-9760.2008.00317.x

WALDRON, Jeremy. Law and disagreement. OUP Oxford, 1999.

YPI, Lea. On the confusion between ideal and non-ideal in recent debates on global justice. Political Studies, Oxford, v. 58, n. 3, p. 536-555, 2010. https:// doi.org/10.1111/j.1467-9248.2009.00794.x

\section{Endereço postal}

André Matos de Almeida Oliveira

Avenida João Pinheiro, $N^{\circ} 100$

Bairro Centro - Belo Horizonte

Minas Gerais - CEP: 30130-180 